\title{
Estresse do Professor de Contabilidade: Modulação sob a Ótica da Teoria Demanda-Controle-Suporte
}

\author{
Eduardo Mendes Nascimento \\ https://orcid.org/0000-0002-2188-9748 \\ Marcia Garcia Carvalho \\ https://orcid.org/0000-0001-5266-3939 \\ Edgard Cornacchione \\ https://orcid.org/0000-0002-0745-131X
}

\section{Resumo}

Objetivo: Identificar e analisar a influência que os níveis de demanda, controle e suporte exercem sobre o estresse autorrelatado pelos docentes dos cursos de Ciências Contábeis das Instituições de Ensino Superior (IES) do Brasil.

Método: Utilizou-se de um survey com questões relativas à condição biopsicossocial dos 614 professores participantes, sobre a percepção de estresse destes com o Teacher Stress Inventory, e de demanda, controle e suporte emocional com o Job Demand-Control-Support.

Resultados: $\mathrm{O}$ suporte e o controle contribuem, de forma significativa ( $<<0,01)$, para diminuir o estresse percebido pelos professores. Contudo, as demandas presentes nas IES contribuem para majorar $(\mathrm{p}<0,01)$ o estresse. Foi apurado, também, que a idade, a percepção positiva sobre o estado de saúde mental e a satisfação geral com a profissão e com os próprios alunos são fatores capazes de modular, negativamente, o estresse do professor $(\mathrm{p}<0,01)$. Porém, ser mulher, lecionar pela manhã e ser professor em uma IES pública aumentam a percepção de estresse dos respondentes $(\mathrm{p}<0,01)$.

Contribuições: Considerando que a capacidade de adaptação das pessoas é limitada, este trabalho permite descortinar as circunstâncias que podem agravar os efeitos causados pelo estresse, tendo em vista o acréscimo de demandas físicas e emocionais, resultando, inclusive, em doenças psicossomáticas. Palavras-chaves: Ensino superior; Estresse; Docência; Saúde mental; Ciências Contábeis. 


\section{Introdução}

É recorrente o desafio que os professores universitários têm enfrentado para estimular os estudantes a se envolverem com as facilidades e dificuldades de cada tema da sua disciplina: criar sistemas de avaliação que não só atendam às exigências da instituição, como também reflitam o estado real de aprendizado dos alunos; desenvolver técnicas e práticas pedagógicas que lhes possibilitem interagir com os alunos; criar mecanismos de convivência com as idiossincrasias dos discentes. É também desafiadora a necessidade de saber lidar com estudantes cada ano mais jovens em relação à idade do professor e de realidades sociais diversas (Blevins-Knabe, 1992; Jardilino, Amaral, \& Lima, 2010), com preconceitos etários (Joye \& Wilson, 2015), estereótipos de papéis sociais (El-Alayli, Hansen-Brown, \& Ceynar, 2018) e outras variáveis que afetam o bem-estar dos professores (Goebel \& Carlotto, 2019; Xu, 2019).

Nesse sentido, independentemente de sua origem do estresse, quando recorrente no ambiente laboral, pode causar no indivíduo doenças cardiovasculares, neoplastias e disfunções imunológicas - em especial quando há uma predisposição genética -, além de transtornos mentais (como depressão, baixa autoestima, exaustão emocional - Síndrome de Burnout - e outros) (Maslach \& Jackson, 1981; Landsbergis et al., 1993; Arnetz, 1996; Lipp, 2005; Castro, 2010). Ademais, a percepção do estresse está diretamente associada à resiliência de cada um, ou seja, à capacidade que o indivíduo tem de moldar-se aos eventos estressores. Contudo, não se pode duvidar que até a capacidade de adaptação é limitada.

Observa-se que nem sempre o estresse é negativo para as pessoas, tanto psicológica quanto fisicamente, visto que algumas situações deflagradoras do estresse podem ser interpretadas como desafios. Aliás, em muitos casos, o estresse acaba promovendo a adaptação ou o desenvolvimento de faculdades cognitivas e comportamentais, permanecendo o indivíduo em bom estado de saúde mental e física, fenômeno conhecido como eustresse (Selye, 1956, Nickel, 2004). Essa adaptação ou aprendizagem é, usualmente, denominada estratégias de coping (Lazarus \& Folkman, 1984).

Quando o professor não consegue desenvolver habilidades fisiológicas e cognitivas para lidar com os elementos estressores e, portanto, está em estado de distresse, ele não é capaz de promover a aprendizagem dos seus alunos com a qualidade esperada. Assim, as repercussões negativas do estresse do docente em sala de aula significam, não raras vezes, prejuízo para suas habilidades como professor.

Sabe-se que a docência é, claramente, uma área de partilha, de experimentação, em que as relações inter e intrapessoais são imperantes, o bem-estar deverá ser predominante para que a aprendizagem aconteça (Pocinho \& Perestrelo, 2011). Desse modo, o estresse é um evento que pode provocar, nos docentes, um interesse maior pela profissão ou, de forma diversa, pode exaurir seus recursos psicofisiológicos, de modo a levar esses profissionais a uma situação de exaustão. 
No caso de alguns docentes do ensino superior no Brasil, outra circunstância que merece destaque é a dupla jornada de trabalho a que eles comumente se submetem. É sabido que faz parte da rotina de muitos profissionais lecionar à noite e desempenhar atividades empresariais paralelas durante o dia, além das atividades envolvendo a pesquisa e extensão e das atividades administrativas (comissões, coordenação e outras) (Santana, 2011; Nascimento, Aragão, Gomes, \& Nova, 2013). Tal situação, apesar de interessante para que os professores possam aplicar seu conhecimento, requalificá-lo e participar das inovações que o tem origem na vivência profissional, pode agravar os efeitos causados pelo estresse, tendo em vista o excesso de demandas físicas e emocionais de vivenciar cotidianamente dois ambientes.

Desse modo, todo o contexto (institucional, de carreira e relacional) da atividade docente em pauta, repercute diretamente na qualidade de ensino em Contabilidade, resultando na capacitação de profissionais mais ou menos preparados para o mercado. Esse contexto acaba gerando frustração para o estudante, ao perceber que sua formação não lhe gerará satisfação pessoal ou rendimentos financeiros de acordo com a sua expectativa, principalmente porque suas potencialidades não foram completamente desenvolvidas. Além disso, o mercado tenderá a desvalorizar (do ponto de vista organizacional e financeiro) esses profissionais pouco qualificados e poderá, quando não houver restrição normativa, buscar profissionais de outras áreas, a fim de satisfazer as necessidades corporativas.

Por todo o exposto, evidencia-se a preocupação em identificar fatores que podem afetar o desempenho do docente nos cursos de Contabilidade e, consequentemente, a qualidade do curso. Desse modo, esta pesquisa buscou evidências para responder à seguinte questão: qual influência os níveis de demanda, controle e suporte exercem sobre o estresse autorrelatado pelos docentes dos cursos de Ciências Contábeis das Instituições de Ensino Superior do Brasil? Nesse sentido, o objetivo do trabalho consistiu em buscar evidências que permitam identificar e analisar a influência que os níveis de demanda, controle e suporte exercem sobre o estresse autorrelatado pelos docentes dos cursos de Ciências Contábeis das IES do Brasil. Adicionalmente, buscou verificar o efeito que as variáveis socioeconômicas exercem sobre o estresse dos professores.

Ao realizar este trabalho, espera-se que os resultados apresentados sejam capazes de melhorar a compreensão sobre o processo de saúde-doença do docente, em decorrência de eventos estressantes, a fim de possibilitar que a comunidade acadêmica mitigue situações de distresse, tornando possível, a um só tempo, que o docente obtenha satisfação pessoal e profissional com seu trabalho, e que a IES garanta, em seu quadro organizacional, educadores que cumpram, adequadamente, suas atividades docentes e administrativas. A consequência direta da concretização dessa expectativa poderá ser que os estudantes terão um ambiente acadêmico propício à sua aprendizagem, ou seja, interessante, estimulante e amigável.

Este trabalho está dividido em 5 seções: introdução, revisão da literatura, procedimentos metodológicos, análise dos dados e considerações finais. A seção 2 apresenta a revisão de literatura que serviu de apoio para este estudo. Na seção 3, constam os aspectos metodológicos, tais como procedimentos para a formação da amostra, instrumentos utilizados, bem como o detalhamento das variáveis do estudo e procedimentos de análises. Na seção 4, são reportados os resultados e a sua análise, incluindo a descrição da população. Por fim, na seção 5, são fornecidas algumas considerações acerca dos dados, limitações e sugestões para estudos futuros. 


\section{Revisão da Literatura}

As bases dos estudos sobre estresse foram traçadas nos trabalhos de Claude Bernard, no final do século XIX, que desenvolveu estudos sobre a adaptação dos seres vivos, afirmando que somente com um meio interior constante e estável o organismo encontraria condições suficientes para manter a sobrevivência (Faro \& Pereira, 2013). Para além dos aspectos biológicos, Walter Cannon descreveu, igualmente, as mudanças comportamentais para lidar com as emergências e tentar restabelecer o equilíbrio, introduzindo a resposta de luta ou fuga para lidar com ameaças, tanto sociais como físicas (Baptista, 2009). Seguidamente, Walter Cannon estudou os mecanismos específicos de resposta face às mudanças no ambiente externo e a sua eficiência na manutenção da estabilidade, nomeadamente os mecanismos sensoriais que comunicam o estado do corpo ao cérebro (Baptista, 2009).

A partir dessa relação do organismo com o meio externo e suas adversidades, Cannon desenvolveu o conceito de homeostase, o que permitiu estudar as mudanças nos sistemas nervoso e endócrino que regulam o metabolismo para responder às mudanças ambientais e as deteriorações na saúde quando o sistema entra em desregulação (Quick, Spielberger, 1994). O que ele conseguiu comprovar foi que o corpo tem um sistema básico de defesa de manutenção dos níveis basais de funcionamento fisiológico, intitulado homeostasia, que mantém um estado de equilíbrio, permitindo a adaptação do organismo diante das constantes mudanças do ambiente externo, absorvidas direta ou indiretamente pelo meio interno (Faro \& Pereira, 2013).

No início do século XX, o fisiologista Walter Cannon de Harvard expandiu as opiniões de Claude Bernard sobre um ambiente interno estável [...] em sua investigação da resposta do sistema medular simpático-adrenal às situações de emergência. Este sistema mobiliza rapidamente recursos de energia do corpo, aumentando a epinefrina (adrenalina), que por sua vez aumenta a pressão arterial, frequência cardíaca e o açúcar no sangue, além de acelerar a coagulação do sangue, eliminar os produtos de fadiga dos músculos e diminuir a digestão ${ }^{1}$ (Ganzel, Morris \& Wethington, 2010).

Dessas constatações, Selye (1956) constatou que existia um padrão semelhante e consistente de resposta aos desafios ao equilíbrio do corpo, a homeostase, independentemente do modo como este desafio era efetuado. Os animais respondiam de modo inespecífico aos desafios, quer fossem aumentos de temperatura, agentes infecciosos ou tóxicos, com um padrão de resposta universal que designou por síndrome de adaptação geral (Baptista, 2009). Esta era constituída por três estados: alarme, em que o agente estressor era registrado e, assim, era organizada uma defesa; um segundo, de resistência, em que o organismo produzia as mudanças necessárias para lidar e eliminar o agente; e, finalmente, um último estágio, de exaustão, quando o agente estressor não conseguia ser eliminado e que poderia conduzir à morte (Baptista, 2009).

Selye (1956) indicava que o estresse é a existência de um conjunto orquestrado de respostas endocrinológicas que são ativadas frente à ação de estímulos nocivos, que alteram o estado de homeostase. A partir desse conceito, inicialmente concebido como uma síndrome biológica, Selye (1956) incitou no meio científico a necessidade de se estudar as respostas adaptativas, sendo que o interesse residia em descobrir o limiar existente entre a capacidade de sobrevivência e o declínio da saúde mediante os desafios que lhes são impostos.

1 At the beginning of the 20th century, Harvard physiologist Walter Cannon expanded upon Claude Bernard's views of a flexibly stable internal milieu $[\ldots]$ in his investigation of the response of the sympathetic- adrenal medullary system to emergency situations. This system swiftly mobilizes the body's energy resources by increasing epinephrine (adrenaline), which in turn increases blood pressure, heart rate, and blood sugar, as well as hastening blood coagulation, clearing fatigue products from muscles, and decreasing digestion. 
Do ponto de vista funcional, o estresse foi desenvolvido biologicamente para ativar e mobilizar rapidamente a atenção do indivíduo para uma tarefa cognitiva que preserve a sua vida ao identificar um evento considerado ameaçador. Portanto, a função principal do estresse é a de promover a adaptação do indivíduo a uma situação possivelmente ameaçadora (do ponto de vista orgânico). Desse modo, o estresse se presta a manter a homeostase do organismo, ou seja, resume o esforço empregado pelo organismo nos processos fisiológicos com a intenção de restaurar o estado de equilíbrio interno, preservando a vida (Lipp, 2005; Ganzel, Morris \& Wethington, 2010).

O estresse é, pois, uma reação normal do organismo humano, fundamental e indispensável para sua a sobrevivência, sem o qual o indivíduo não teria condições de enfrentar uma situação de grande perigo (Meleiro, 2007). O que significa dizer que a ausência do estado de alerta que o estresse provoca no corpo, a desatenção e, eventualmente, a paralisação motora do indivíduo, em uma situação de grande perigo, poderia resultar na ausência de resposta que preservaria sua vida.

Contudo, surge um paradoxo em relação à possibilidade de adaptação fisiológica e psicológica dos indivíduos. Quando se pensa no estresse como meio de sobrevivência dos indivíduos em situações, por exemplo, de risco de morte, em que uma pessoa deve buscar sua sobrevivência (ataque de um animal selvagem), o modelo de estresse que indica que a respiração se tornará acelerada e as pupilas e os vasos sanguíneos se dilatarão revela, ademais, que todo esse esforço orgânico ocorrerá para preservar o organismo de modo que este possa retornar ao estado de equilíbrio (homeostase).

Assim, ratifica-se o impacto sobre o funcionamento biológico, mas o enfoque explicativo parte prioritariamente do indivíduo para o meio. Logo, uma conceituação fundamental para a psicologia é o estresse como uma relação particular entre o indivíduo e o ambiente, tornando-se essencial compreender todo e qualquer recurso psicológico e social que intermedeie este contato (Faro \& Pereira, 2013).

Nessa linha de raciocínio, França e Rodrigues (2005, p. 30) consideram o estresse como o "estado do organismo, após o esforço de adaptação, que pode produzir deformações na capacidade de resposta, atingindo o comportamento mental e afetivo, o estado físico e o relacionamento com as pessoas". Essa definição leva Nickel (2004) a considerar que esses autores abordam o estresse tanto como processo, que consiste na tensão (estado no qual o indivíduo é desviado do seu nível natural de relaxamento) diante de uma situação desafiadora de ameaça ou conquista, quanto como condição, categoria na qual as respostas ao estresse são classificadas em eustresse ou distresse. Assim, a autora acredita que o eustresse surge quando as pessoas reagem bem à demanda, o que caracteriza uma resposta positiva, que leva o indivíduo a ser mais produtivo e criativo nas suas respostas adaptativas. De outro lado, o distresse ocorre quando a resposta é negativa, desencadeando um processo adaptativo inadequado, que pode provocar a exaustão (Nickel, 2004).

Portanto, o estresse é um processo que se desenvolve em etapas. É possível vivenciar episódios de estresse temporários, de baixa ou de grande intensidade, bem como estar na etapa de resistência ao fator gerador de desequilíbrio ou, ainda, no estado de exaustão intensa, que possibilita, inclusive, o surgimento de doenças (Lipp, 2005). Rudow (1999) sintetiza que o estresse deve ser estudado como um processo relacional, e o que se busca é entender, dentro do panorama explicativo das diferenças individuais, o porquê da variabilidade de resposta aos fatores estressores, como exposição psicossocial a risco à saúde ou intensidade da resposta adaptativa. Desse modo, o foco se volta para as particularidades da interação entre o aparato psicológico, o entorno social e o funcionamento biológico, privilegiando-se, sobretudo, a busca pela elucidação de como funciona e se diferencia, quantitativa e qualitativamente, a capacidade de adaptação individual (Faro \& Pereira, 2013). 
Observa-se, assim, a existência de uma relação em forma de U invertido entre a exposição ao estressor e a adaptação, de modo que quantidades adequadas de exposição ao estressor (estimulação ou desafio frequentemente) leva ao moderado aumento da saúde e melhora da função fisiológica e mental, sendo que altos e pesistentes níveis de exposição do estressor estão relacionados a resultados negativos de saúde (Ganzel, Morris \& Wethington, 2010), o que é ilustrado na Figura 1.

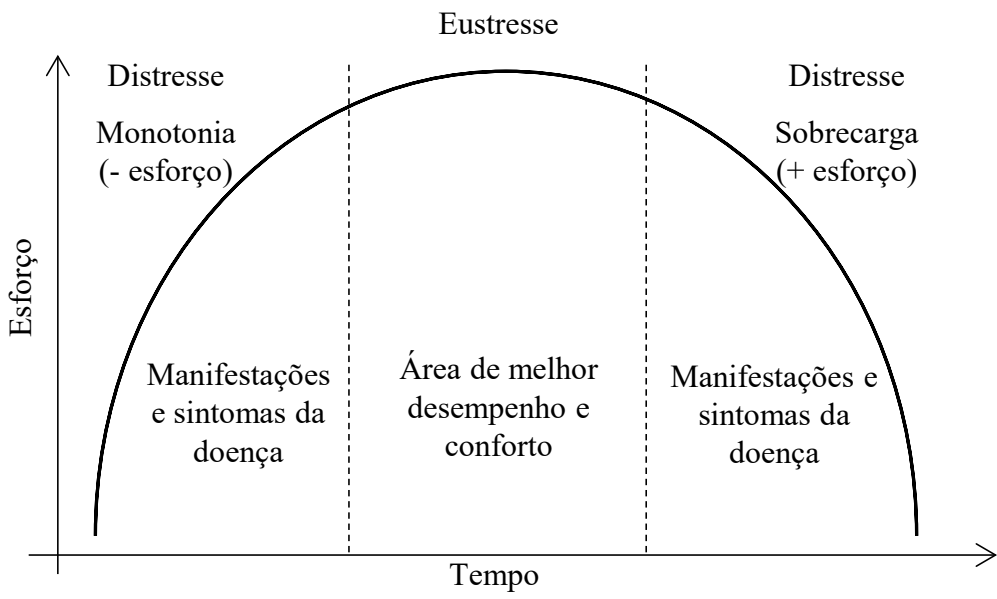

Figura 1. Curva do Estresse

Fonte: França e Rodrigues (2011, p. 42)

Sob a perspectiva aqui analisada, um evento estressor pode ser caracterizado de acordo com seu timing, bem como com a percepção do individuo (se ele é desejável ou não, se ele é benéfico ou não), com a ideia de que a demanda é autoimposta ou imposta externamente, e, ainda, de acordo com o que sua fonte (um amigo, um gerente, uma política, uma norma institucional, etc.) representa para o indivíduo (Lazarus \& Folkman, 1984; Le Fevre; Matheny \& Kolt, 2003). Isso acontece, pois, conforme Ganzel, Morris e Wettington (2010), a modelagem do processo de estresse requer um nível muito mais elevado de especificidade sobre os mecanismos subjacentes da homeostase e manutenção da saúde psicobiológica do indivíduo.

Historicamente, o conceito e a mensuração de saúde têm se baseado na ideia de ausência de doenças. É provável que esse foco no aspecto patológico tenha surgido do fato de que, em épocas passadas, consideravase que a saúde era obtida a partir da superação da doença. Em meados do século XX, no entanto, percebeu-se que o quadro de doenças não acometia as pessoas do mesmo modo que séculos antes, motivando o surgimento de um novo conceito de saúde (Arnetz, 1996). Esse novo panorama, segundo Breslow (1972), encorajou a Organização Mundial de Saúde (WHO, na sigla em inglês) a definir a saúde como sendo "um completo bemestar físico, mental e social e não meramente a ausência de doença ou enfermidade” (WHO, 2015a).

Tal definição, apesar de não ter sido alterada, é objeto constante de crítica (WHO, 2015a). Essas críticas remetem-se, basicamente, ao emprego do termo "completo", já que essa plenitude, conforme argumentam Dalmolin, Backes, Schaurich, Colomé e Gehlen (2011), é uma utopia. Essa concepção, segundo eles, sucinta um equilíbrio, uma existência, diverso daquele construído modernamente, que considera a possibilidade de existir de forma produtiva e feliz apesar das situações de adoecimentos, transtornos ou outras condições que eventualmente o acometem. Por esse ângulo, a saúde é uma avaliação subjetiva que existe para além da evidência orgânica, natural ou objetiva, tampouco se associa a um estado de equilíbrio, na medida em que se trata de um juízo intrínseco por meio do qual a pessoa realizará uma autoavaliação, ponderando seus valores socioculturais e os significados atribuídos ao seu processo de viver (Dalmolin et al., 2011). 
Nessa perspectiva, o processo saúde-doença depende, mais que das análises objetivas ou da articulação com os diferentes determinantes da saúde, das evidências estruturais, isto é, dos fatores externos do entorno social. Mas, submete-se, especificamente, no que concerne às condições de vida e de trabalho, às condições culturais, ambientais, familiar, entre outras. Consequentemente, já que muitos fatores se combinam para afetar a saúde de indivíduos e comunidades, o contexto de vida das pessoas é significativo para explicar seu estado de saúde ou processo de adoecimento. Assim, a compreensão a respeito dessas duas condições do indivíduo (saúde e doença) passa pela análise de seu ambiente social e econômico, ambiente físico e suas características individuais e comportamentais (WHO, 2015b).

Esses fatores se desdobram em outros, criando uma complexa relação entre o próprio indivíduo e seu meio social e físico. Nesse sentido, variáveis, como renda e condição social, educação, ambiente físico, redes de apoio social, genética, serviço de saúde, gênero, entre outras, relacionam-se com a saúde (WHO, 2015b), ou seja, os determinantes e condicionantes do processo saúde-doença são multifatoriais e complexos. Em resumo, saúde e doença configuram processos compreendidos como um continuum, relacionados tanto aos aspectos econômicos, sociais, culturais, quanto à experiência pessoal e aos estilos de vida (Seidl \& Zannon, 2004).

É nesse cenário que o modelo postulado por Karasek (1979, p. 287) é o mais indicado para o contexto educacional universitário, visto que:

O modelo postula que tensão psicológica não resulta de um único aspecto do ambiente de trabalho, mas dos efeitos conjuntos das demandas de uma situação de trabalho e o grau de liberdade para tomada de decisão (discricionariedade) disponível para o trabalhador enfrentar essas demandas. Estes dois aspectos da situação de trabalho representam, respectivamente, os instigadores da ação (demandas de carga de trabalho, conflitos ou outros estressores que colocam o indivíduo motivado ou em um estado energizado de "estresse") e as restrições sobre as ações possíveis. O grau de discricionariedade do indivíduo na decisão no ambiente laboral é a restrição que modula a liberação ou a transformação de 'estresse' (energia potencial) para a energia de ação. Deste modo, este é um modelo de gestão do estresse da tensão baseada no ambiente. Se nenhuma ação pode ser tomada, ou se o indivíduo deve renunciar a outros desejos por causa da baixa discricionariedade na decisão, a energia não liberada pode manifestar-se internamente como tensão mental.

Esse modelo ainda privilegia três dimensões psicossociais no trabalho: o suporte social, o controle sobre o trabalho, e a demanda psicológica advinda do trabalho (Araújo, Graça, \& Araújo, 2003). Essas autoras explicam que, a partir da combinação dessas três dimensões, o modelo distingue situações de trabalho específicas que, por sua vez, estruturam riscos diferenciados à saúde. Para avaliar esses aspectos, Karasek Jr. (1979) elaborou um inventário: o Job Strain Model (Modelo Demanda-Controle, rebatizado, mais tarde de Job Damand-Control-Support).

Karasek Jr. (1979), ainda, baseando-se, inicialmente, na percepção do trabalhador acerca do nível de demanda e controle, elaborou uma escala de medida do estresse, baseado no American Quality of Employment Survey, com 49 questões. Posteriormente, Theorell et al. (1988), a partir de uma versão sueca do questionário original, com aplicação de uma escala Likert, reduziram as 49 questões para 17 e incluíram a dimensão suporte (cinco questões para a dimensão demanda, outras seis questões para a dimensão controle, e mais seis para suporte).

Por meio dessas escalas é possível classificar o estado de percepção de estresse em quatro situações: alta demanda e baixo controle (alta exigência); baixa demanda e alto controle (baixa exigência); alta demanda e alto controle (trabalhos ativos); baixa demanda e baixo controle (trabalhos passivos) (Karasek Jr. (1979). Ainda segundo esse modelo, atividades de alta exigência representam o maior risco para os desfechos de saúde (Macedo et al., 2007). 
Diversos estudos têm utilizado a base desenvolvida por Karasek Jr. (1979), inclusive na área de educação. Greco, Magnago, Prochnow, Beck e Tavares (2010) constataram uma associação positiva entre o desfecho avaliado e a alta exigência no trabalho (alta demanda psicológica e baixo controle), quando comparados aos docentes classificados em situação de baixa exigência no trabalho (baixa demanda psicológica e alto controle).

Outras pesquisas, que buscaram identificar a percepção do nível de estresse nos professores do ensino superior, encontraram dados significativos: mais de 50\% dos profissionais entrevistados apresentaram nível crônico de estresse (Gmelch; Wilke, \& Lovrich, 1986; Blix et al., 1994; Carloto, 2004) - realidade que é verificada em contextos variados, como, no Brasil, no trabalho de Garcia e Benevides-Pereira (2003), que encontrou níveis de exaustão emocional em $1 / 3$, de despersonalização em $1 / 5$ e reduzida realização profissional em 1/4 da amostra. Carlotto (2004) ao olhar o estresse dos professores universitário sob a ótica do burnout também encontrou níveis altos na amostra e acrescentou que os dados referentes à exaustão profissional em professores universitários nos forneceram alguns indicadores importantes como quanto menor o grau de autonomia e de identificação da tarefa do professor com atividade docente, maior é sua exaustão emocional. Ainda sobre a realidade dos professores universitários brasileiro, Soares, Mafra e Faria (2019), encontraram que a pontuação média obtida pelos participantes do estudo foi superior à relatada para a maioria das ocupações analisadas por eles. Quer dizer, os resultados pintam um panorama perigoso para os professores universitários no Brasil, pois que o estresse enfraquece o sistema de defesa do corpo, ativa mecanismos que desencadeiam a inflamação ou, alternativamente, desativa os mecanismos que inibem a inflamação minando as condições de saúde deles (Soares, Mafra \& Faria, 2019).

Em comparação a outros contextos, eles apresentam situação análoga ao contexto do Brasil. Por exemplo, El-Ibiary, Yam e Lee (2017), que olharam para os professores do curso de farmácia, nos Estados Unidos, e diagnosticaram que $41 \%$ dos professores estavam em risco de exaustão decorrente do estresse. Nessa pesquisa, as autoras levantaram que o risco dessa exaustão é maior para as mulheres, professores com menos tempo de profissão, aqueles com filhos pequenos e que trabalham alto número de horas por semana. Ainda no contexto americano, Blix, Cruzeiro, McBeth e Blix (1994) entenderam que os professores da amostra deles apresentavam boa adaptação ao estresse acadêmico, mas percebiam estressores em seu contexto laboral por pelo menos $50 \%$ do tempo que estavam inseridos neles. Por causa desse constante estado de alerta, os professores relataram burnout, problemas de saúde relacionados ao estresse, diminuição da produtividade no trabalho, incapacidade de lidar com o estresse no trabalho e consideração da mudança de emprego. Mas Blix et al. (1994) determinaram que essa dificuldade em manejar o estresse poderia ser modulada caso os professores pudessem gerenciar suas demandas.

Resultado que caminha no mesmo sentido que Mcclenahan, Giles e Mallett (2007) em uma amostra de uma universidade do Reino Unido. Esses autores encontraram níveis moderados de estresse (média de $36 \%$ da escala), porém ainda aí identificaram o efeito moderador que demandas, controle e suporte podem ter, conforme proposto por Karasek Jr. (1979). O que, segundo aqueles autores, corroborando com as pesquisas que mostram que altos níveis de percepção de estresse e estressores persistentes no trabalho estão ligados a problemas de saúde e até a insatisfação com o trabalho. Entendimento idêntico seguido por Moeller \& Chung-Yan (2013), que acharam que maior controle situacional percebido junto com alto suporte social pode melhorar a capacidade percebida dos indivíduos de lidar com o estressor. Quer dizer, enquanto o controle das demandas e suporte emocional amortecem o efeito das tensões laborarias, as demandas as exacerbam. É relevante destacar que o levantamento de Moeller e Chung-Yan (2013) foi realizado no Canadá, e que o nível de estresse autorrelatado dos professores foi da aproximadamente $70 \%$ da escala. Quer dizer, a teoria de Karasek Jr. (1979) encontra indícios de sua aplicabilidade mesmo em contextos diferentes, sejam com altos níveis de estresse (Moeller \& Chung-Yan, 2013), sejam com baixos níveis (Mcclenahan, Giles \& Mallett, 2007). 
Os resultados demonstram que os docentes vivenciam quadros de depressão, dores musculares, exaustão emocional, insônia, baixa autoestima e outros problemas psicofisiológicos, associados aos altos níveis de estresse. Essa grave situação que vitima um elevado número de docentes em todo o mundo, segundo Karasek Jr. (1979), deve-se a dois fatores principais: excesso de demandas e baixo grau de suporte emocional, e autonomia atribuída à pessoa para controlar essas demandas - fenômeno que recebeu o nome de Modelo Demanda-Controle-Suporte.

Ainda, os resultados das pesquisas citadas deixam claro que, comparativamente (Soares, 2016, Soares, Mafra \& Faria, 2019), a severidade do estresse entre os profissionais de ensino é superior a diversas profissionais, o que coloca o magistério como uma das profissões de alto risco para apresentar síndromes/ transtornos e demais consequências do estresse persistente. Quer dizer, pela alta demanda que enfrentam e por ser uma atividade estritamente relacional (com alunos, colegas, coordenadores, chefes, secretarias e outros), os professores podem perceber níveis altos de estresse, esgotando seus recursos físicos, psíquicos e emocionais para o enfrentamento, o que pode resultar em consequência que a menos danosa poderia ser $o$ seu afastamento das atividades, mas podendo chegar ao comprometimento da sua saúde mental e até suicídio.

Especificamente no contexto do curso superior em Ciências Contábeis e demais cursos da área de Ciências Humanas Aplicadas, já se sabe que o estresse é um dos problemas de alta prevalência e que incomoda os professores (Farias et al., 2019). Ao pensar no contexto universitário brasileiro, seja pela variedade de seus componentes (ensino, pesquisa, extensão, orientação de alunos e gestão universitária), nota-se que é permeado de estressores repercutindo, certamente, na vivência docente. Essa situação pode resultar em um quadro de sofrimento para o docente ao se deparar com o estresse agudo (Ferreira et al. (2020), a insegurança e a exaustão física e mental (Coutinho, Magro, \& Budde, 2011). Essa circunstância merece atenção, pois a forma que o docente percebe seu trabalho afeta diretamente seu desempenho laboral e, inclusive, sua vida pessoal (Paiva \& Saraiva, 2005; Petroski, 2005).

Sobre o exposto, Greco et al. (2010) destacam que, apesar de o trabalho docente propiciar certa liberdade e criatividade (no sentido pedagógico e em sala de aula), permitindo maior controle sobre algumas questões inerentes ao trabalho, os docentes estão, ao mesmo tempo, submetidos a atividades extraclasse, extensa jornada de trabalho, cumprimento de tarefas com prazo curto de tempo e múltiplos empregos. $\mathrm{O}$ somatório dessas características, certamente, pode favorecer os efeitos negativos sobre a saúde docente.

\section{Procedimentos Metodológicos}

O instrumento de coleta de dados foi constituído por dois blocos: variáveis descritivas e percepção de estresse; e foi aplicado, por meio eletrônico, a partir dos e-mails identificados nos sites institucionais das IES, obtendo-se, desse modo, retorno de 614 professores de diversas regiões do Brasil. O instrumento foi registrado na Plataforma Brasil sob o número CAAE: [suprimido para garantir o blind review]. A primeira parte do instrumento foi constituída de questões que versavam sobre o perfil biopsicossocial do respondente e aspectos relacionados ao seu trabalho, variáveis que estão associadas ao estresse (Gmelch, Wilke, \& Lovrich, 1986; Gillespie et al., 2001; Calais, Andrade, \& Lipp, 2003; Garcia \& Benevides-Pereira, 2003; Kataoka et al., 2014; Saeed \& Farooqi, 2014; Shen et al., 2014; Silva et al. , 2014; Faro, 2015; Goebel \& Carlotto, 2019, Xu, 2019; Layte et al., 2019). 
O estresse percebido pelos professores foi determinado pela utilização da escala de Boyle, Borg, Falzon e Baglioni Jr. (1995), isto é, o Teacher Stress Inventory (TSI), com 26 questões, divididas em cinco dimensões, com uma escala Likert de cinco pontos, na versão traduzida por Silva Morgado e Gomes (2009). Esse instrumento, além de apresentar uma boa validade em relação aos levantamentos teóricos, demonstrou ter, também, um bom ajustamento empírico (por exemplo: Griffith, Steptoe, \& Cropley, 1999; Silva, Morgado, \& Gomes, 2009; Klassen \& Chiu, 2010; Boshoff et al., 2018; Clément et al., 2020), em face do Alfa de Cronbrach, superior a 0,8 nessas pesquisas. Com essa base, o resultado da percepção de estresse do respondente pode ser expresso pela equação, como segue:

$$
E E_{i}=\sum E_{i}
$$

Em que:

EEi é o escore alcançado pelo respondente $i$, nos aspectos elaborados nas questões pertinentes a todos os itens do Teacher Stress Inventory; e

Ei é a nota atribuída a cada um dos itens do Teacher Stress Inventory pelo respondente $i$.

Para se determinar se o estresse percebido pelos docentes poderia ser mediado pelo controle de demandas e suporte emocional, optou-se por utilizar a Teoria da Demanda-Controle-Suporte (Job Demand-Control-Support - DC-S), conforme Karasek Jr. (1979), porém, baseando-se na versão resumida, desenvolvida por Theorell, Perski, Åkerstedt, Sigala, Ahlberg-Hultén, Svensson e Eneroth (1988) e traduzida para o português por Mello Alvesa, Chorb, Faersteinc, Lopesc e Werneckd (2004). A versão brasileira do instrumento apresentou Alfa de Cronbrach mínimo de 0,67 (na dimensão controle) e alto grau de validade para o contexto brasileiro, considerando o grande número de pesquisas que utilizou essa teoria.

No modelo de Karasek Jr. (1979), considera-se que o estresse é regulado pela demanda, cujo efeito é mediado por sua interação com o controle que o indivíduo tem sobre ela (demanda) e com o suporte (apoio social) que o indivíduo recebe (este último acrescentado pela complementação ulterior do modelo). Assim, empregados que trabalham em ambientes caracterizados por alta demanda, baixo controle e baixo apoio social experimentam o mais alto nível de tensão. O DC-S é composto de 17 questões, divididas em três dimensões: demanda, controle e suporte, as quais devem ser avaliadas em uma escala Likert (nunca, quase nunca, raramente, às vezes, frequentemente),

Por isso e para possibilitar que os respondentes fossem classificados em um dos vértices do modelo (baixa exigência, trabalho ativo, trabalho passivo ou alta exigência), para a análise e inclusão dos dados no modelo, todas as dimensões foram incluídas no modelo de forma separada. Desse modo, para a análise do Modelo Demanda-Controle, segundo os vértices do modelo, foram utilizadas as equações expressas em 2, 3 e 4 :

$$
E D_{i}=\sum D_{i}
$$

Em que:

$E D i$ é o escore alcançado pelo respondente $i$, nos aspectos elaborados nas questões pertinentes à dimensão Demanda; e

$D i$ é a nota atribuída aos itens da dimensão Demanda pelo respondente $i$. 
O escore das dimensões Controle e Suporte se dará por:

$$
E C_{i}=\sum C_{i}
$$

Em que:

$E C i$ é o escore alcançado pelo respondente $i$, nos aspectos elaborados nas questões pertinentes à dimensão Controle; e

Ci é a nota atribuída aos itens da dimensão Controle pelo respondente $i$.

$$
E S_{i}=\sum S_{i}
$$

Em que:

ESi é o escore alcançado pelo respondente $i$, nos aspectos elaborados nas questões pertinentes à dimensão Suporte; $\mathrm{e}$

Cié a nota atribuída aos itens da dimensão Suporte pelo respondente $i$.

Com base nessa proposta, o respondente que declarasse que tinha baixa demanda (por exemplo, a soma dos itens dessa dimensão - Demanda - totalizasse até 12 pontos, considerando-se que ela chega a 25 pontos), por outro lado, altos níveis de controle e de suporte (a soma dos itens dessas duas dimensões - Controle e Suporte - somadas fossem maior que 30 pontos, considerando-se que cada uma dessas dimensões podem alcançar, individualmente, até 30 pontos) estaria dentro da classificação proposta por Karasek Jr. como baixa exigência, conforme Figura 1.

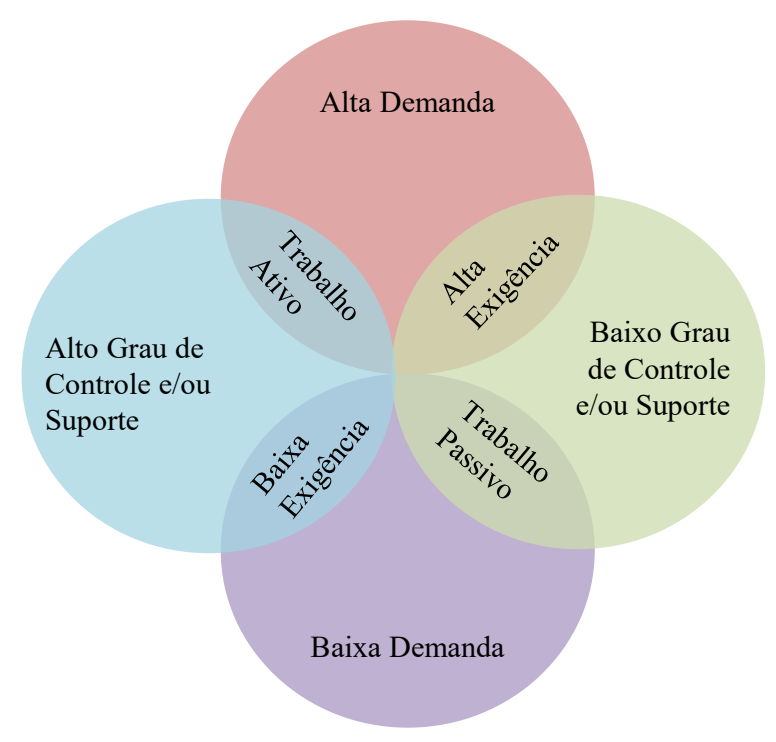

Figura 2. Classificação pelo DC-S

Fonte: baseado em Kasarek Jr. (1979). 
Em relação à análise dos dados, optou-se por um modelo de regressão linear múltipla, conforme equação 5, além de análises de frequência absoluta e relativa. Após estimar a regressão linear, foram realizados testes para se verificar problemas relacionados à heterocedasticidade, multicolinearidade e ao erro de especificação,

$$
E E_{I}=\alpha+D C S X_{1 i}+\beta_{2} X_{2 i}+\beta_{3} X_{3 i}+\cdots+\beta_{k} X_{k i}+e
$$

Em que:

EEi é o nível de estresse percebido pelo respondente;

$\alpha$ é a constante do modelo;

DCS são as avariáveis associadas ao Job Demand-Control-Suport;

$B j(\mathrm{j}=1,2, . . ., \mathrm{k})$ são os coeficientes de cada variável explicativa de controle;

$X j(j=1,2, . ., \mathrm{k})$ são as variáveis explicativas;

$i(\mathrm{i}=1,2, . . ., \mathrm{k})$ representa cada uma das observações da amostra em análise; $\mathrm{e}$

$e$ é o termo de erro do modelo estimado.

Em relação à análise de diferença entre as médias dos grupos, foi empregado, inicialmente, o teste de normalidade Shapiro-Francia, de modo a verificar a distribuição das variáveis quantitativas (p-valor menor que 0,05$)$. Para as variáveis quantitativas que não seguiam distribuição normal, foi realizado o Teste de Mann-Whitney ou Testes de Spearman, quando as variáveis possuíam dois grupos; e o Teste de Kruskal-Wallis, nos demais casos (quando ao menos uma das variáveis é qualitativa e a outra quantitativa); e, caso as variáveis seguissem a distribuição normal, o Teste $t$ de Student. Em momentos em que se buscava analisar a associação entre variáveis qualitativas, fez-se uso do Teste ANOVA (Chi-Square) para determinar se essa associação era significativa do ponto de vista estatístico.

\section{Análise dos Dados}

Inicialmente, constatou-se que os participantes tinham idade média de 44 anos aproximadamente (77\% tinham idade acima de 37 anos), a maioria era do sexo masculino (57\%), casado ou em união estável (73\%), com ao menos 1 filho/dependente (70\%) e renda familiar média de, aproximadamente, R\$10,8 mil. Em relação ao perfil profissional da amostra, enquanto $52 \%$ trabalhavam em um período do dia, a outra parcela (48\%) dedicava-se a dois ou mais turnos de aula. Os respondentes estavam vinculados a uma IES privada, na maioria dos casos (62\%), e declararam ter escolhido ser professor por vocação (78\%). Já em relação à titulação, apenas $32 \%$ dos professores possuíam doutorado e, de modo geral, apresentavam uma média de experiência com docência de 14,5 anos (a idade média em que os professores iniciaram a carreira foi de 30 anos, mediana igual a 29 e desvio padrão de 6,7). Constatou-se que o quadro dos cursos de Ciências Contábeis era composto de professores de diversas áreas de conhecimento, considerandose a maior titulação: Administração (23\%), Ciências Contábeis (45\%); Direito (3\%); Economia (4\%); Engenharia de Produção (5\%) e outras áreas (21\%).

A partir das respostas dos professores em relação à sua carga de trabalho, foi possível perceber que os respondentes dedicavam, em média, 16,1 horas/aulas à atividade de lecionar (na maioria das vezes $-50 \%$ dos respondentes - lecionavam apenas no turno da noite). Em relação a esse item, notou-se que havia variação em decorrência do sexo dos respondentes (mulheres declararam lecionar, em média, 17,2 horas/aulas, ao passo que os homens, 15,2, p-valor=0,01). Quem lecionava em um turno, passava, em média, 14,8 horas/ aulas em sala de aula; já quem dedicava dois turnos à docência, o fazia em média por 17,6 horas/aulas por semana. Já quem frequentava os três turnos do dia em uma sala de aula permanecia nela por cerca de 17,5 horas/aulas/semanas. Essas diferenças foram consideradas significativas estatisticamente ( $p$-valor=0,01). 
Também se percebeu que havia diferença na quantidade de horas lecionadas pelos professores das IES privadas em relação aos demais, o que foi considerado significativo estatisticamente ( $\mathrm{p}$-valor $=0,00$ ). Esses professores declararam permanecer 17,4 horas/aulas em sala de aula, enquanto um professor substituto lecionava 16,5 horas/aulas e um servidor público (professor efetivo), 13,8 horas/aulas em média. Ao serem questionados se desenvolviam outra atividade laborativa, 55\% dos respondentes declararam possuir outra atividade.

Em relação à percepção sobre o próprio estado de saúde física e mental pelos respondentes, constatouse que a maior parte se considerava saudável, pois em relação à saúde mental, $78 \%$ a considerava boa ou muito boa, apesar de a percepção sobre a saúde física pelos respondentes ter sido ligeiramente menor (72\%). Em relação a uma percepção negativa, destacam-se os respondentes que se perceberam com uma saúde física muito ruim, ruim ou razoável, que representaram, aproximadamente, 1/3 dos respondentes. Essa mesma avaliação cai a, aproximadamente, 1/4 para a autopercepção sobre a saúde mental.

\subsection{Grau de Estresse dos Respondentes}

Nesta pesquisa, o Alpha de Cronbach médio foi de 0,945 (Tabela 1) para os 26 itens, sendo que, individualmente, para as seis dimensões, a que apresentou menor grau de estrutura interna foi a "Ausência de Recursos", e a que revelou maior grau foi a dimensão "Mau Comportamento dos Estudantes". O teste de normalidade das variáveis indicou que elas não seguem distribuição normal ( $\mathrm{p}$-valor $<0,01$ ).

A partir da Tabela 1, observa-se, inicialmente, que o nível geral de estresse médio (variável produzida a partir da soma dos escores das dimensões do Teacher Stress Inventory) dos docentes que participaram da pesquisa foi de 82 pontos, o que representa $63 \%$ do nível máximo medido pelo instrumento utilizado. Ademais, a dimensão que mais contribuiu para o estresse do docente foi o mau comportamento dos estudantes, e a que menos contribuiu foi a relação com os colegas.

Tabela 1

Nível de Estresse Percebido pelos Professores por Dimensão

\begin{tabular}{|c|c|c|c|c|c|c|c|c|}
\hline \multirow[b]{2}{*}{ Dimensão } & \multirow[b]{2}{*}{ Score } & \multicolumn{5}{|c|}{ Dados por Respondente } & \multirow{2}{*}{$\begin{array}{l}\text { Alpha de } \\
\text { Cronbach }\end{array}$} & \multirow{2}{*}{$\begin{array}{c}\text { Teste } \\
\text { Normalidade }\end{array}$} \\
\hline & & $\begin{array}{l}\text { Score } \\
\text { Médio }\end{array}$ & $\begin{array}{l}\text { Desvio } \\
\text { Padrão }\end{array}$ & $\begin{array}{c}\text { Score } \\
\text { Máximo }\end{array}$ & $\begin{array}{c}\text { Score } \\
\text { Mínimo }\end{array}$ & $\begin{array}{l}\text { Taxa } \\
\text { Média }\end{array}$ & & \\
\hline $\begin{array}{l}\text { Mau comportamento } \\
\text { dos estudantes }\end{array}$ & 12.268 & 20,0 & 6,0 & 30,0 & 6.0 & $67 \%$ & 0,895 & 0,00 \\
\hline Carga de trabalho & 12.022 & 19,6 & 5,5 & 30,0 & 6.0 & $65 \%$ & 0,856 & 0,00 \\
\hline $\begin{array}{l}\text { Reconhecimento } \\
\text { profissional }\end{array}$ & 9.511 & 15,5 & 4,6 & 25,0 & 5.0 & $62 \%$ & 0,818 & 0,00 \\
\hline Ausência de recursos & 9.365 & 15,3 & 4,6 & 25,0 & 5.0 & $61 \%$ & 0,800 & 0,00 \\
\hline $\begin{array}{l}\text { Relações com os } \\
\text { colegas }\end{array}$ & 7.097 & 11,6 & 4,0 & 20,0 & 4.0 & $58 \%$ & 0,828 & 0,00 \\
\hline Nível Geral de Estresse & 50.261 & 82,0 & 20,6 & 130,0 & 29.0 & $63 \%$ & 0,945 & 0,00 \\
\hline
\end{tabular}

Conforme levantamento bibliográfico, esse nível de estresse autorrelatado é menor apenas do que o encontrado por Lorenz, Benatti e Sabino (2010), em estudo feito com enfermeiros de um hospital universitário brasileiro, e do que o relatado no trabalho de Caeiro (2010), que levantou os dados com professores de ensino fundamental de Portugal. Tal indicação aponta para a necessidade de futuras investigações, de modo a se verificar como o nível de estresse da profissão de professor universitário se posiciona em relação às demais profissões. Esse alto nível de estresse percebido pela amostra é condizente com trabalhos como os de Gmelch, Wilke e Lovrich, (1986); Blix et al. (1994); Carloto (2004), Moeller e Chung-Yan (2013), El-Ibiary, Yam e Lee (2017) Soares, Mafra e Faria (2019) 
O Modelo Demanda-Controle-Suporte é um modelo tridimensional, desenhado por Robert Karasek Jr. para avaliar aspectos psicossociais do trabalho (Karasek Jr. 1979; Theorell et al., 1988; Melo et al., 2004). Esse modelo relaciona os níveis de controle e suporte do trabalhador sobre o próprio trabalho, e de demandas psicológicas oriundas do ambiente laboral, e as repercussões sobre a estrutura psíquica e orgânica dos trabalhadores.

Essa demanda psicológica se identifica com as situações no ambiente laboral em que o trabalhador é exigido psiquicamente: concentração intensa; pressão do tempo para realização de tarefas; ritmo e volume de tarefas a serem realizadas (Reis et al., 2006). Por essa razão, o controle e o suporte funcionam como mediadores do estresse sofrido pelo indivíduo, servindo como instrumentos capazes de balancear ou suplantar o sofrimento. O controle envolve dois grupos de fatores: 1) uso de habilidades: criatividade, aprendizado de coisas novas, tarefas diferentes e desenvolvimento de habilidades especiais; e 2) autoridade decisória: liberdade de decidir como fazer as tarefas, possibilidade de opinar sobre o trabalho e de influenciar a política gerencial (Reis et al., 2006). A dimensão suporte também tem dois grupos de fatores, que buscam medir a relação com os colegas de trabalho: afetividade envolvendo o relacionamento e apoio recebido; e a situação geral do ambiente laboral percebido.

Por esse meio, Karasek Jr. (1979) e Theorell et al., (1988) propõem a avaliação simultânea de níveis de demanda e de controle-suporte, relacionando essas dimensões de modo a avaliar os níveis/tipos de situações de trabalho específicos. Ao combinar níveis de demanda e controle-suporte, diferentes situações de trabalho são constituídas: 1) alta exigência: combinando alta demanda e baixo controle-suporte; 2) trabalho ativo: combinando alta demanda e elevado controle-suporte; 3 ) trabalho passivo: combinando baixa demanda e baixo controle-suporte; e 4) baixa exigência: combinando baixa demanda e elevado controle-suporte.

A partir dessa teoria, constata-se que o DC-S apresentou Alfa de Cronbach geral de 0,785, sendo que a dimensão com menor Alfa foi Controle $(0,615$ - Tabela 2$)$ e a de maior, Suporte $(0,887)$. Em relação ao teste de normalidade, constatou-se que as dimensões, com base nas respostas de 614 professores, não seguem distribuição normal ( $\mathrm{p}$-valor $<0,01)$.

Tabela 2

Nível de Demanda, Controle e Suporte Apresentado pelos Professores por Dimensão

\begin{tabular}{lcccccccc}
\hline \multicolumn{1}{c}{ Dimensão } & Score & $\begin{array}{c}\text { Score } \\
\text { Médio }\end{array}$ & $\begin{array}{c}\text { Desvio } \\
\text { Padrão }\end{array}$ & $\begin{array}{c}\text { Score } \\
\text { Máximo }\end{array}$ & $\begin{array}{c}\text { Score } \\
\text { Mínimo }\end{array}$ & $\begin{array}{c}\text { Taxa } \\
\text { Média }\end{array}$ & $\begin{array}{c}\text { Alpha de } \\
\text { Cronbach }\end{array}$ & $\begin{array}{c}\text { Teste } \\
\text { Normali-dade }\end{array}$ \\
\hline Demanda & 9.038 & 14,7 & 2,1 & 20 & 7 & $74 \%$ & 0,712 & 0,000 \\
\hline Controle & 12.125 & 19,7 & 2,3 & 24 & 6 & $82 \%$ & 0,615 & 0,000 \\
\hline Suporte & 11.505 & 18,7 & 3,5 & 24 & 7 & $78 \%$ & 0,887 & 0,000 \\
\hline
\end{tabular}

É possível observar que a média das notas atribuídas às dimensões foram relativamente altas, pois a dimensão que teve menor média em relação ao máximo possível foi "demanda", que teve média de 14,7, o que representa $74 \%$ do escore máximo que poderia ser obtido. Referente aos fatores das dimensões, o item "Com que frequência você tem que trabalhar intensamente (isto é, produzir muito em pouco tempo)?" foi o que os professores indicaram que mais frequentemente precisam fazer. Na dimensão Controle, o fator "Seu trabalho exige muita habilidade ou conhecimentos especializados?" foi o que apresentou maior média. Já para Suporte, o item "No trabalho, eu me relaciono bem com meus chefes" foi o que obteve maior média. 
Em relação à prevalência do tipo de Demanda-Controle-Suporte, é possível observar, na Tabela 3, que $82 \%$ dos professores podem ser classificados em Trabalho Ativo, ou seja, os respondentes parecem ter identificado muitos estressores no ambiente acadêmico, mas não são significativamente afetados devido ao nível de Controle-Suporte de que usufruem. Esses dados, portanto, são indicativos de que a amostra não tem sofrido, de forma contundente, com o estresse que decorre da atividade de professor universitário.

Tabela 3

Prevalência do Tipo de Demanda-Controle dos Professores

\begin{tabular}{lccc}
\hline & Classificação & \multicolumn{2}{c}{ Frequência } \\
\cline { 2 - 3 } & Geral & $\%$ \\
\hline Baixa Exigência & 74 & $12 \%$ \\
\hline Trabalho Ativo & 501 & $81 \%$ \\
\hline Trabalho Passivo & 11 & $2 \%$ \\
\hline Alta Exigência & 28 & $5 \%$ \\
\hline Total & 614 & $100 \%$ \\
\hline
\end{tabular}

\subsection{Análise Inferencial}

De modo a determinar o efeito que Demanda, Controle e Suporte (DCS) poderiam ter no fomento (Demanda) e na modulação (Controle e Suporte) do estresse percebido pelos docentes, foi estimada a regressão, conforme informado na metodologia e apresentado no Apêndice 1. Após a estimação dos dados, foi realizado teste para determinar eventuais restrições em relação à heterocedasticidade (Teste de White), multicolinearidade (VIF) e erro de especificação (Ramsey RESET). O modelo apresentou problema de heterocedasticidade (p-valor de 0,0061 ). Desse modo, o modelo analisado foi o apresentado, conforme exposto na Tabela 4, estimado pelo método Stepwise robusto, admitindo-se significância de 5\%. Isso posto, foi analisado o problema de multicolinearidade que apresentou valores abaixo de 1,26 (para a variável Suporte) e 1/VIF de 0,791134 (VIF médio de 1,13). Por último, o teste de erro de especificação indicou que o modelo (pelo Stepwise Robusto) apresentava esse problema $(0,0098)$, todavia assumiu-se que tal questão surge ao se preferir o modelo apenas com variáveis significativas. 
Tabela 4

\section{Estimação do Modelo Robusto pelo Método Stepwise}

\begin{tabular}{|c|c|c|}
\hline Variável & Coeficiente & Erro Padrão \\
\hline Suporte & $-1,24236 * * *$ & 0,20856 \\
\hline Demanda & $3,29505 * * *$ & 0,34544 \\
\hline Controle & $-0,86741 * * *$ & 0,29324 \\
\hline Renda Familiar & $-0,00046 * * *$ & 0,00011 \\
\hline Sexo & $4,42681 * * *$ & 1,46682 \\
\hline Lecionar pela Manhã & $9,99983 * * *$ & 2,50788 \\
\hline Lecionar em IES Pública & $3,21721 * *$ & 1,50533 \\
\hline Percepção sobre sua Saúde Mental & $-2,73916 * * *$ & 0,94234 \\
\hline Satisfação com seus Alunos & $-2,39690 * * *$ & 0,81109 \\
\hline Satisfação com a Profissão & $-1,80456 * \star$ & 0,86285 \\
\hline Constante & $102,37570 * * *$ & 8,60855 \\
\hline Prob> F & & 0,0000 \\
\hline $\mathrm{R}^{2}$ & & 0,3484 \\
\hline $\mathrm{R}^{2}$ Ajustado & & - \\
\hline
\end{tabular}

À vista disso, considerando a amostra levantada para este estudo, constatou-se que a Teoria de Karasek Jr. (1985) apresentou relação explicativa significativa com o estresse percebido pelos professores ( $\mathrm{p}$-valor $<0,01$ ). Isso quer dizer que a demanda teve um efeito positivo (coeficiente de 2,64 ) sobre o estresse ao passo que, quanto maior a percepção de Controle (coeficiente de -0,72) e, principalmente, de Suporte $(-1,40)$, menor foi a percepção de estresse, resultado harmônico com os trabalhos de Moeller e ChungYan (2013), Lima e Lima-Filho (2009), Katoaka et al. (2014) e Rodrigues, Hinojosa e Ramírez (2014).

Esse resultado indica que, quando combinadas com as demandas do trabalho, as características de controle e apoio, definidas no modelo de Karasek Jr. (1985), influenciam a relação estressor-tensão de forma semelhante para diferentes tipos de estressores presentes no ambiente universitário, como, por exemplo: mau comportamento dos alunos, carga de trabalho, reconhecimento profissional, ausência de recursos e relacionamento com os colegas, conforme as dimensões do Teacher Stress Inventory. De fato, o modelo DC-S propõe que, quando altas exigências são associadas a um alto controle-suporte (isto é, trabalhos ativos), os indivíduos são motivados a enfrentar o desafio de "conquistar" as demandas.

Com efeito, o controle-suporte no/do trabalho age como uma válvula para aliviar a pressão das demandas, deslocando os obstáculos (estressores) para motivar a adaptação e manter o indivíduo em eustresse. Portanto, embora a situação de estresse possa contribuir com o processo de distresse e possível adoecimento (Garcia \& Benevides-Pereira, 2003; Murofuse, Andranches, \& Napoleão, 2005), os estressores podem funcionar também como motivadores, já que são estímulos e provocam a adaptação em outro nível, em outro estado, com certeza superior, por ter enfrentado e vencido a demanda. Os estressores, sejam eles ambientais, psicológicos ou contextuais, têm apenas a capacidade de desencadear a reação ao estresse, quer dizer, a resposta de estresse será mediada à maneira como cada indivíduo tiver habilidades para manejar situações novas ou adversas, a partir da capacidade de enfrentamento que a pessoa dispõe ou que aprendeu a empregar durante sua história de vida (Aragão et al., 2009). 
Se a experiência, os conhecimentos anteriores e a dedução das circunstâncias forem similares às já vivenciadas, a discrepância entre o que é observado ou vivido e o que é esperado ou programado será reduzida, eliciando respostas compensatórias que são específicas para cada estímulo e para cada organismo (Garcia, 2008). Por isso, a questão que se faz pertinente, a partir das evidências apresentadas, é que a IES deve garantir que o professor perceba que possui controle e suporte no seu ambiente laboral, de modo a mediar a compreensão de estresse vivenciada na academia, evitando nível crônico do estresse.

Os resultados deixam patente que o estresse percebido pelos professores era razoável (note-se que a constante foi significativa e tem valor de 102.37), razão pela qual eles necessitavam de mediadores para que tivessem recursos a fim de manter sua homeostase. Isso é de extrema importância tendo em vista a mudança do papel do professor que, conforme Byrne et al. (2013), integrou estressores ocupacionais que, tradicionalmente, não eram característicos das universidades.

Sobre as variáveis descritivas, inicialmente, o modelo indica que a Renda Familiar é significativa para minorar a percepção de estresse. Assim, primeiro cabe destacar que ela deve ser entendida como um preditor de bem-estar social, considerando que não havia outras variáveis que pudessem captar o efeito desse constructo e considerando que ele é indicativo de acesso à saúde, lazer, educação e segurança. Dessa forma, Renda Familiar indicou que é um mediador para a percepção de estresse dos respondentes, considerando seu coeficiente $(-0,00046)$ e sua significância ( $p$-valor $=0,000)$.

Pelo que considera Faro (2015), a cada passo na redução do status socioeconômico, maior é a vulnerabilidade dos indivíduos. Por outro lado, segundo o citado autor, o que se espera é que, com o crescimento da renda, seja reduzida a exposição a contextos estressógenos, uma vez que melhores recursos materiais minimizam a existência de estressores associados à baixa qualidade de vida e à exposição a adversidades sociais ligadas à pobreza. Portanto, embora a renda não reflita completamente o impacto do status socioeconômico sobre o estresse, ela representa uma variável importante na quantificação da exposição e na ativação dos recursos psicossociais de adaptação, proporcionados pela situação financeira (Faro, 2015, Layte et al., 2019).

No que tange ao fato de as mulheres terem uma percepção de estresse maior que a dos homens, alguns autores relatam algumas possíveis explicações sociais e biológicas. Autores como Gmelch, Wilke e Lovrich (1986) e Calais, Andrade e Lipp (2003) trazem que, do ponto de vista social, a mulher tem mais demandas que os homens, apesar de já se ter alcançado avanços na diminuição de desigualdades de gênero. Gmelch, Wilke e Lovrich, (1986) consideram que as mulheres atendem também às demandas familiares, não cobradas de seus pares em mesma proporção, além de, na própria instituição, as mulheres participarem de mais atividades. Destaca-se, ainda, que o ambiente acadêmico é sensivelmente machista, dando preferência aos homens quanto à distribuição de recursos e mesmo na relação interpessoal entre os seus colegas e alunos (Gmelch, Wilke, \& Lovrich,1986).

Calais, Andrade e Lipp (2003) reportam que, do ponto de vista biológico, mulheres teriam maior sensibilidade a problemas psicológicos relacionados à depressão e à ansiedade por causa do estrogênio, $\mathrm{o}$ qual pode produzir uma neuroproteção para disfunções de desenvolvimento (esquizofrenia, por exemplo) e disfunções degenerativas (Alzeimer, por exemplo), em decorrência de suas funções cíclicas, aumentando a resposta ao estresse.

Em relação a lecionar no período da manhã, a pesquisa apresentou que os professores que lecionam nesse período têm sensibilidade ao estresse maior que os professores que lecionam nos outros horários. Isso pode ser explicado pela influência do ciclo circadiano que, normalmente, tem seu pico ao acordar e diminui durante o dia até ter seu menor nível à noite, resultando em maior sensibilidade ao estresse na parte da manhã (Dalri, 2013).

O fato de lecionar em uma IES pública foi indicado, no modelo, como uma situação que majorava o estresse do professor, quando comparado que outros tipos de vínculos, o que é condizente com outras pesquisas (Gillespie et al., 2001; Kataoka et al., 2014). Esse fato, possivelmente, decorre do contexto da carreira dos professores (Moeller \& Chung-Yan, 2013) de IES públicas que, apesar de se beneficiarem de estabilidade no emprego, são demandados em atividades como gestão e extensão, além do papel de docente e pesquisador. 
Sobre a autopercepção a respeito da saúde mental, a pesquisa apresentou que, quanto mais positiva era essa percepção pelo professor, tanto menor era seu estresse relatado. Conforme Lazarus e Folkman (1984), a percepção e a interpretação cognitiva do indivíduo ante uma dada situação são determinantes para o desencadeamento da reação de estresse. Dessa forma, ao se perceber em condições de saúde mental adequadas, o professor consegue mobilizar energia para melhor lidar com os estressores ocupacionais.

A última variável analisada, satisfação, mostrou-se mediadora negativa do estresse. A satisfação do professor no trabalho é conceituada como sendo os julgamentos avaliativos positivos ou negativos que eles fazem sobre seus empregos. Seria natural esperar, então, que essa interação se refletisse em um dos fatores a intensificar ou atenuar, como no presente caso, o estresse do docente (Gmelch, Wilke, \& Lovrich, 1986). Especialmente, destacam ainda Gmelch, Wilke e Lovrich (1986), a satisfação do professor em relação aos seus alunos seria uma avaliação sobre o grau de valorização que ele obteve pelo esforço necessário e investido para preparar a aula. Assim, quanto maior a satisfação do professor com os próprios alunos, maior seria sua percepção de valorização, fazendo-o experienciar sentimento de reconhecimento sobre o próprio esforço pela qualidade do ensino.

\section{Considerações Finais}

A presente pesquisa objetivou buscar evidências que permitissem identificar e analisar os níveis que demanda, controle e suporte exercem sobre o estresse autorrelatado pelos docentes do curso de Ciências Contábeis das Instituições de Ensino Superior do Brasil e sua relação com suas variáveis socioeconômicas. A princípio, a prevalência do estresse entre os docentes que responderam ao questionário foi moderada, pois, considerando-se o nível máximo medido pelo instrumento utilizado (Teacher Stress Inventory), o escore médio alcançado foi de $63 \%$.

Interessante observar que diversos fatores demográficos apresentaram associação significativa ( $\mathrm{p}$-valor $<0,1)$ entre a percepção de estresse, quando analisados isoladamente: idade; sexo; quantidade de dependentes; renda familiar; tipo de IES; tempo de docência; quantidade de horas em sala de aula; possuir outra profissão além da de docente; percepção sobre a saúde física e mental e satisfação com a profissão, IES, gestor, alunos, colegas, disciplina e remuneração.

Esse resultado confirma o que já era esperado: o estresse do professor se apresenta como um fenômeno complexo (Seidl \& Zannon, 2004), lançando grande preocupação social. Isso porque, quando o ambiente acadêmico é permeado por constantes eventos estressores, tal circunstância pode desencadear reações psicofisiológicas negativas nos docentes, afetando seu desempenho e sua interação com o ambiente organizacional e, consequentemente, a aprendizagem dos alunos.

Em relação ao objetivo primário deste trabalho, as evidências permitem sustentar que há relação significativa ( $\mathrm{p}$-valor $<0,01)$ e negativa entre a percepção de estresse e o grau de controle e suporte reconhecido pelos professores. De outro lado, quanto mais os respondentes notaram carga de demanda no ambiente laboral, tanto maior foi sua percepção de estresse ( $\mathrm{p}$-valor $<0,01$ ).

Não que os professores não se enxerguem significativamente demandados, pois $81 \%$ podem ser classificados em Trabalho Ativo. Observa-se que o escore médio para a percepção de demandas dos respondentes foi de 14,7 (uma prevalência média de 74\% do escore máximo medido pelo DC-S), contudo, em razão da regulação produzida pelo controle e apoio social no ambiente de trabalho, isso não causou sofrimento nos docentes. Quer dizer, mesmo que no ambiente haja níveis altos de demanda, os professores tendem a permanecer em estado de eustresse, preservando a sua saúde física e mental. 
O fato é que o professor, em geral, possui grande autonomia (escore médio de $82 \%$ da escala) para definição de suas atividades dentro e fora da sala de aula (na condução das atividades cotidianas). Além disso, identificar um ambiente agradável e permeado de boas relações com os colegas de trabalho (incluindo o gestor) é o que explica o baixo nível de percepção de sofrimento mental em relação ao estresse. Portanto, quanto maior for o controle sobre o próprio trabalho e o suporte de que o professor desfrutar, menor tenderá a ser a produção dos hormônios do estresse, com consequências positivas sobre a saúde mental e física dos trabalhadores.

Ainda assim, os resultados apresentados não podem ser compreendidos como se os professores não requeressem cuidado, atenção e investimento em seu ambiente de trabalho. $\mathrm{O}$ fato de os professores se apresentarem como eficazes na lida com o estresse no ambiente acadêmico evidencia a necessidade de contribuir para a manutenção de tal contexto. Nesse sentido, vale ressaltar que foram levantados indícios de que a autopercepção de saúde física e mental apresenta alguma inadequação para, ao menos, 1/4 dos respondentes, o que pode indicar possível exaustão emocional. O estresse quebra a homeostase interna, exigindo do indivíduo esforço, em termos de adaptação. Uma vez que a adaptabilidade do organismo é finita, se o estressor não for suprimido ou se o indivíduo não souber administrá-lo, este poderá chegar à exaustão física e psicológica, momento em que as doenças se manifestam, podendo se tornar permanentes e até fatais, possibilitando também o aparecimento de patologias psicossomáticas.

À vista do apresentado, considerando-se a importância que o trabalho representa para a situação socioeconômica e o bem-estar dos professores, as dificuldades promovidas pelo estresse são dolorosas e, por isso, é vital atuar sobre ele, mitigando-o, inclusive porque não há dúvidas de que a qualidade do ensino superior depende, significativamente, da presença de um corpo docente de alto nível. Posta a questão nesses termos, entende-se que os diversos agentes da docência envolvidos, no âmbito das instituições de ensino (aqui incluído o próprio professor), devem buscar mecanismos que possibilitem o enfrentamento positivo dos fatores de estresse, especialmente aqueles inerentes à profissão.

As limitações deste trabalho se fundamentam em dois aspectos: amostra e instrumento de coleta. $\mathrm{O}$ primeiro aspecto se deve ao fato de não haver um banco de dados constituído, no Brasil, com os dados e com as características dos professores do curso de Ciências Contábeis. Assim, não é possível determinar uma amostra probabilística que permita analisar como o estresse alcança todos os docentes. Desse modo, o presente trabalho se utilizou de uma amostra não probabilística por acessibilidade, o que não permite a extrapolação dos resultados aqui apresentados. Por essa razão, buscou-se alcançar o maior número de respondentes possível.

A limitação pertinente ao instrumento está associada ao fato de diversas métricas (tal como o próprio índice de estresse) serem autorrelatadas, o que eventualmente produz uma visão aproximada do evento, já que um questionário coleta a percepção do respondente. Para mitigar tal problema, foram utilizados instrumentos já validados, de modo a ampliar a confiabilidade dos dados coletados e também sua comparabilidade.

Como indicação de futuros trabalho, propõe-se que se busque aprofundar o conhecimento sobre a situação de burnout e a depressão, desencadeadas pela persistência de estressores acadêmicos. Outra possibilidade poderia ser investigar melhor a situação do estresse relatado pelas mulheres (cis e trans), que estão lecionando nos cursos de Contabilidade. A pesquisa identificou algo que já está bem documentado: o sofrimento mental das mulheres é maior que a dos homens, por isso, saber de que modo essa situação está presente nas universidades poderia gerar estratégias de enfrentamento direcionadas à mitigação dessa prevalência. Também, como a situação da maioria dos professores foi classificada como trabalho ativo, por meio de uma pesquisa longitudinal, pode se investigar como os professores reagem, ao longo de sua carreira, com as adversidades que encontram, como: assédio moral, desmotivação com a carreira, estratégias de enfrentamento e as mudanças pós-pandemia. 


\section{Referências}

Araújo, T. M., Graça, C. C., \& Araújo, E. (2003). Estresse ocupacional e saúde: contribuições do Modelo Demanda-Controle, Ciência \& Saúde Coletiva, 8(4), 991-1003.

Arnetz, B. B. (1996). Causes of Change in the Health of Populations: a biopsychosocial viewpoint, Social Science \& Medicine, 43 (5), 605-608. Doi: https://doi.org/10.1016/0277-9536(96)00108-6

Baptista, A. (2009). Stresse: aspectos psicobiológicos. Bem-Estar e Qualidade de Vida: Contributos da Psicologia da Saúde. Alcochete: Textiverso, Lda, 51-65.

Blix, A. G., Cruise, R. J., Mitchell, B. M., \& Blix, G. G. (1994). Occupational stress among university teachers. Educational research, 36(2), 157-169. Doi: https://doi.org/10.1080/0013188940360205

Blevins-Knabe, B. (1992). The ethics of dual relationships in higher education. Ethics \& Behavior, 2(3), 151-163. Doi: https://doi.org/10.1207/s15327019eb0203_2

Boshoff, S. M., Potgieter, J. C., Ellis, S. M., Mentz, K., \& Malan, L. (2018). Validation of the Teacher Stress Inventory (TSI) in a multicultural context: The SABPA study. South African Journal of Education, 38(1). Doi: https://doi.org/10.15700/saje.v38ns2a1491

Boyle, G. J., Borg, M. G., Falzon, J. M. \& Baglioni Jr. A. J, (1995), A structural model of the dimensions of teacher stress, British Journal of Educational Psychology, 65(1), 49-67. Doi: https://doi. org/10.1111/j.2044-8279.1995.tb01130.x

Breslow, L. (1972). A quantitative approach to the World Health Organization definition of health: physical, mental and social well-being, International Journal of Epidemiology, 1(4), 347-355. Doi: https://doi. org/10.1093/ije/1.4.347

Byrne, M., Chughtai, A., Flood, B., Murphy, E., \& Willis, P. (2013). Burnout among accounting and finance academics in Ireland, International Journal of Educational Management. 27(2), 127-142. Doi: https:// doi.org/10.1093/ije/1.4.347

Caeiro, R. M. D. N. (2010). Stress ocupacional e avaliação de desempenho nos professores: contributos para uma psicodinâmica do trabalho. (Dissertação). Universidade de Lisboa.

Carlotto, M. S. (2004). Síndrome de burnoute caraterísticas de cargo em professores universitários. Revista Psicologia Organizações e Trabalho. 4(2), 145-162.

Castro, F. J. G. (2010). Burnout, Projeto de Ser e Paradoxo Organizacional. (Tese). Universidade Federal de Santa Catarina, Florianópolis.

Clément, L., Fernet, C., Morin, A. J. \& Austin, S. (2020). In whom college teachers trust? On the role of specific trust referents and basic psychological needs in optimal functioning at work. Higher Education, 1-20. Doi: https://doi.org/10.1007/s10734-019-00496-Z

Dalmolin, B. B., Backes, D. S., Zamberlan, C., Schaurich, D., Colomé, J. S., \& Gehlen, M. H. (2011). Significados do conceito de saúde na perspectiva de docentes da área da saúde. Doi: Escola Anna Nery Revista de Enfermagem, 15(2), 389-394. http://dx.doi.org/10.1590/S1414-81452011000200023

Dalri, R. D. C. D. M. (2013). Carga horária de trabalho dos enfermeiros de emergência e sua relação com estresse e cortisol salivar. (Tese). Universidade de São Paulo.

Dunn, P. J. C., Whelton, W. J., \& Sharpe, D. (2006). Maladaptive perfectionism, hassles, coping and psychological distress in university professors. Journal of counseling psychology, 53(4), 511. Doi: https://psycnet.apa.org/doi/10.1037/0022-0167.53.4.511 
El-Alayli, A., Hansen-Brown, A. A., \& Ceynar, M. (2018). Dancing backwards in high heels: Female professors experience more work demands and special favor requests, particularly from academically entitled students. Sex Roles, 79(3-4), 136-150. Doi: https://doi.org/10.1007/s11199-017-0872-6

El-Ibiary, S. Y., Yam, L., \& Lee, K. C. (2017). Assessment of burnout and associated risk factors among pharmacy practice faculty in the United States. American journal of pharmaceutical education, 81(4). Doi: https://doi.org/10.5688/ajpe81475

El-Sayed, S. H., El-Zeiny, H. H. A. \& Adeyemo, D. A. (2014). Relationship between occupational stress, emotional intelligence, and self-efficacy among faculty members in faculty of nursing Zagazig University, Egypt. Journal of Nursing Education and Practice, 4(4), 183.

Farias, R. A. S., Sallaberry, J. D., de Sousa, W. G., de Freitas, M. M., \& Dias, C. N. (2019). Dificuldades dos professores do curso de Ciências Contábeis: uma agenda de pesquisa. Revista Docência do Ensino Superior, 9, 1-20. Doi: https://doi.org/10.35699/2237-5864.2019.12249

Faro, A. (2015). Estresse e Distresse: Estudo com a Escala de Faces. Temas em Psicologia, 23 (2), 341-354.

Faro, A, \& Pereira, M, E, (2013), Estresse: Revisão narrativa da evolução conceitual, perspectivas teóricas e metodológicas, Psicologia, Saúde \& Doenças, 14(1), 78-100.

Ferreira, M. M., Nasu, V. H., Suave, R., Altoe, S. M. L., \& Hillen-cristina, C. (2020). Prevalência da Síndrome de Burnout em Professores de Cursos de Ciências Contábeis: a Atuação na Pós-graduação Stricto Sensu Faz Diferença?. Anais. XLIV ENCONTRO DA ANPAD - EnANPAD.

Folkman, S., Lazarus, R, S., Dunkel-Schetter, C., DeLongis, A., \& Gruen, R, J, (1986). Dynamics of a stressful encounter: cognitive appraisal, coping, and encounter outcomes. Journal of personality and social psychology, 50(5), 992-1003. Doi: https://psycnet.apa.org/doi/10.1037/0022-3514.50.5.992

França, A. C. L., \& Rodrigues, A. L. (2011). Stress e trabalho: uma abordagem psicossomática. In Stress e trabalho: uma abordagem psicossomática. Atlas.

Ganzel, B. L., Morris, P. A., \& Wethington, E. (2010). Allostasis and the human brain: Integrating models of stress from the social and life sciences. Psychological review, 117(1), 134. Doi: https://dx.doi. org $/ 10.1037 \% 2 \mathrm{Fa} 0017773$

Garcia, L. P., \& Benevides-Pereira, A. M. T. (2003). Investigando o Burnout em professores universitários, Revista Eletrônica InterAção Psy, 1(1), 76-89.

Graham, J. E., Christian, L. M., \& Kiecolt-Glaser, J. K. (2006). Stress, age, and immune function: toward a lifespan approach. Journal of behavioral medicine, 29(4), 389-400. Doi: https://doi.org/10.1007/ s10865-006-9057-4

Gillespie, N. A., Walsh, M. H. W. A., Winefield, A. H., Dua, J., \& Stough, C. (2001). Occupational stress in universities: staff perceptions of the causes, consequences and moderators of stress, Work \& stress, 15(1), 53-72. Doi: https://doi.org/10.1080/02678370117944

Gmelch, W. H., Wilke, P. K., \& Lovrich Jr. N. P. (1986), Dimensions of stress among university faculty: Factor-analytic results from a national study, Research in Higher Education, 24(3), 266-286. Doi: https://doi.org/10.1007/BF00992075

Goebel, D. K., \& Carlotto, M. S. (2019). Preditores sociodemograficos, laborais e psicossociais da Síndrome de Burnout em docentes de educação a distancia. Avances en Psicología Latinoamericana, 37(2), 295-312. Doi: https://doi.org/10.12804/revistas.urosario.edu.co/apl/a.6886

Griffith, J., Steptoe, A., \& Cropley, M, (1999), An investigation of coping strategies associated with job stress in teachers, British Journal of Educational Psychology, 69(4), 517-531. Doi: https://doi. org/10.1348/000709999157879 
Jardilino, J. R. L., do Amaral, D. J., \& Lima, D. F. (2010). A Interação Professor-Aluno em Sala de Aula no Ensino Superior: o curso de administração de empresas. Diálogo Educacional, Curitiba, 10(29), 101-119. Doi: http://dx.doi.org/10.7213/rde.v10i29.3064

Joye, S., \& Wilson, J. H. (2015). Professor age and gender affect student perceptions and grades. Journal of the Scholarship of Teaching and Learning, 126-138.

Karasek Jr. R. A. (1979). Job demands, job decision latitude, and mental strain: Implications for job redesign. Administrative science quarterly, 285-308. Doi: https://doi.org/10.2307/2392498

Kataoka, M., Ozawa, K., Tomotake, M., Tanioka, T., \& King, B. (2014). Occupational stress and its related factors among university teachers in Japan. Health, 6(05), 299. Doi:10.4236/health.2014.65043

Kimmel, P. (1995). A framework for incorporating critical thinking into accounting education. Journal of Accounting Education. 13(3), 299-318, 15. Doi: https://doi.org/10.1016/0748-5751(95)00012-B

Klassen, R. M., \& Chiu, M. M. (2010). Effects on teachers' self-efficacy and job satisfaction: Teacher gender, years of experience, and job stress. Journal of educational Psychology, 102(3), 741. Doi: https://doi. org/10.1037/a0019237

Landsbergis, P. A., Schurman, S. J., Israel, B. A., Schnall, P. L., Hugentobler, M. K., Cahill, J. \& Baker, D. (1993). Job stress and heart disease: evidence and strategies for prevention. New solutions: a journal of environmental and occupational health policy: NS, 3(4), 42-58. Doi: https://doi.org/10.2190\%2FNS3.4.d

Lazarus, R. S. \& Folkman, S. (1984). Stress, Appraisal and Coping. 1. ed. Nova York: Springer.

Layte, R., McCrory, C., Cheallaigh, C. N., Bourke, N., Kivimaki, M., Ribeiro, A. I., Stringhini, S. \& Vineis, P. (2019). A comparative analysis of the status anxiety hypothesis of socio-economic inequalities in health based on 18,349 individuals in four countries and five cohort studies. Scientific reports, 9(1), 1-12. Doi: https://doi.org/10.1038/s41598-018-37440-7

Le Fevre, M., Matheny, J., \& Kolt, G. S. (2003). Eustress, distress, and interpretation in occupational stress. Journal of Managerial Psychology, 18(7), 726-744. Doi: https://doi.org/10.1108/02683940310502412

Lima, M. D. F. E. M., \& Lima-Filho, D. D. O. (2009). Condições de trabalho e saúde do/a professor/a universitário/a. Ciências \& Cognição, 14(3), 62-82.

Lipp, M. E. N. (2005). O Modelo Quadrifásico do Stress, In: Mecanismos Neuropsicofisiológicos do Stress: Teoria e Aplicação Clínica. 2. ed. São Paulo: Casa do Psicólogo.

Lorenz, V. R., Benatti, M. C. C. \& Sabino, M. O. (2010). Burnout e estresse em enfermeiros de um hospital universitário de alta complexidade, Rev, Latino-Am, Enfermagem, 18(6), 1084-91. Doi: https://doi. org/10.1590/S0104-11692010000600007

McClenahan, C. A., Giles, M. L., \& Mallett, J. (2007). The importance of context specificity in work stress research: A test of the Demand-Control-Support model in academics. Work \& stress, 21(1), 85-95. Doi: https://doi.org/10.1080/02678370701264552

Maslach, C., Jackson, S. E. (1981) The Measurement of Experienced Burnout, Journal of Organizational Behavior, 2(2), 99-113. Doi: https://doi.org/10.1002/job.4030020205

Meleiro, A. M. A. (2007). O Stress do Professor. In: O Stress do Professor. Marilda Lipp (Organização). $5^{a}$ Edição. Campinas: Papirus.

Mello, A. M. G., Chorb, D., Faersteinc, E., de S Lopes, C., \& Werneckd, G. L. (2004). Versão resumida da "job stress scale”: adaptação para o português. Rev Saúde Pública, 38(2), 164-71. 
Moeller, C., \& Chung-Yan, G. A. (2013). Effects of social support on professors' work stress. International Journal of Educational Management, 27(3), 188-202. Doi: https://doi. org/10.1108/09513541311306431

Nascimento, A. S., Aragão, I. R. B. N., Gomes, C. A. S. \& Nova, S. P. D. C. C. (2013). Pesquisa Científica e a Construção do Conhecimento: Possibilidade e Prática ou Utopia?, Revista Evidenciação Contábil \& Finanças, 1(2), 106-122.

Nickel, D. C. (2004). Percepção de estresse e atitudes de aprendizagem de docentes na mudança do sistema seriado para o modular: estudo de caso numa instituição de ensino superior. Tese (doutorado) Universidade Federal de Santa Catarina, Centro Tecnológico. Programa de Pós-Graduação em Engenharia de Produção.

Paiva, K. C. M., \& Saraiva, L. A. S. (2005). Estresse ocupacional de docentes do ensino superior. Revista de Administração-RAUSP, 40(2), 145-158.

Petroski, E. C. (2005). Qualidade de vida no trabalho e suas relações com estresse, nível de atividade física e risco coronariano de professores universitários. (Tese). Universidade Federal de Santa Catarina.

Pocinho, M., \& Perestrelo, C. X. (2011). Um ensaio sobre burnout, engagement e estratégias de coping na profissão docente. Educação e Pesquisa, 37(3), 513-528. Doi: https://doi.org/10.1590/S151797022011000300005

Quick, J. C., \& Spielberger, C. D. (1994). Walter Bradford Cannon: pioneer of stress research. International Journal of Stress Management, 1(2), 141-143. Doi: https://doi.org/10.1007/BF01857607

Reddy, G. L., \& Poornima, R. (2012). Occupational stress and professional burnout of University Teachers in South India. International Journal of Educational Planning \& Administration, 2(2), 109-124.

Reis, E. J., Araújo, T. M. D., Carvalho, F. M., Barbalho, L., \& Silva, M. O. (2006). Docência e exaustão emocional. Educação \& Sociedade, 27(94), 229-253. Doi: http://dx.doi.org/10.1590/S010173302006000100011

Rocha, Y. A. C., Coelho, J. A., Santos, K. F. \& Ferreira, M. S. (2007). Relação Professor/Aluno, Ciência \& Consciência, 2.

Rodríguez, M. C., Hinojosa, L. M. M., \& Ramírez, M. T. G. (2014). Evaluación del desempeño docente, estrés y burnout en profesores universitarios/Evaluation of teacher performance, stress and burnout in university professors, Revista actualidades investigativas en educación, 14(1), 16.

Rudow, B, (1999), Stress and burnout in the teaching profession: European studies, issues, and research perspectives, In: Understanding and Preventing Teacher Burnout. Vandenberghe, R., Huberman, A. M. University of Cambridge: Cambridge.

Saeed, K., \& Farooqi, Y. A. (2014). Examining the relationship between work life balance, job stress, and job satisfaction among university teachers (A case of University of Gujarat). International Journal of Multidisciplinary Sciences and Engineering, 5(6), 9-14.

Santana, A. L. A. (2011). O perfil do professor de Ciências Contábeis e seu reflexo no Exame Nacional de Desempenho dos Estudantes-um estudo nas universidades federais do Brasil. (Dissertação). Universidade de São Paulo.

Seidl, E. M. F., \& Zannon, C. M. L. D. C. (2004), Qualidade de vida e saúde: aspectos conceituais e metodológicos, Cadernos de saúde pública, 20(2), 580-588.

Selye, H. (1956). The stress of life. McGraw-Hill. 
Silva, J., Morgado, J. \& Gomes, C. (2009). Satisfação, stress profissional e colaboração em docentes do $2^{\circ}$ e $3^{\circ}$ ciclo: Que relações, In: Actas do X Congresso Internacional Galego-Português de Psicopedagogia (pp, 1286-1301).

Silva, M. F. M. D., Teles, L. M. D. S., Aragão, S. D. B. X., \& Silva, C. F. D. L. S, (2014). Estudo avaliativo da predisposição à síndrome de burnout em professores de uma Universidade de Parnaíba-PI. Revista Psicologia e Saúde, 6(2), 28-36. Doi: https://doi.org/10.20435/pssa.v6i2.353

Shen, X., Yang, Y. L., Wang, Y., Liu, L., Wang, S., \& Wang, L. (2014). The association between occupational stress and depressive symptoms and the mediating role of psychological capital among Chinese university teachers: a cross-sectional study. BMC psychiatry, 14(1), 329. Doi: https://doi.org/10.1186/ s12888-014-0329-1

Soares, M. B. (2016). Análise do estresse ocupacional em docentes da Universidade Federal de Viçosa e suas interferências na qualidade de vida e suporte familiar. Dissertação. Mestrado em Economia Doméstica da Universidade Federal de Viçosa.

Soares, M. B., Mafra, S. C. T., \& Faria, E. R. D. (2019). Fatores associados à percepção de estresse em docentes universitários em uma instituição pública federal. Revista Brasileira de Medicina do Trabalho, 17(1), 90-98. Doi: https://doi.org/10.5327/Z1679443520190280

Theorell, T., Perski, A., Åkerstedt, T., Sigala, F., Ahlberg-Hultén, G., Svensson, J., \& Eneroth, udy, Scandinavian journal of work, environment \& health, 189-196.

Tytherleigh, M. Y., Webb, C., Cooper, C. L., \& Ricketts, C. (2005). Occupational stress in UK higher education institutions: A comparative study of all staff categories. Higher Education Research \& Development, 24(1), 41-61. Doi: https://doi.org/10.1080/0729436052000318569

World Health Organization (WHO). (2015a). Constitution of the World Health Organization. Available from: Doi: https://apps.who.int/gb/bd/PDF/bd47/EN/constitution-en.pdf?ua=1, Accessed on: 15 Jan. 2021. , (2015b). The determinants of health. Recuperado em 15/01/2021de: https://www.who.int/news$\mathrm{room} / \mathrm{q}$-a-detail/determinants-of-health

$\mathrm{Xu}, \mathrm{L}$. (2019). Teacher-researcher role conflict and burnout among Chinese university teachers: a job demand-resources model perspective. Studies in Higher Education, 44(6), 903-919. Doi: https://doi. org/10.1080/03075079.2017.1399261 
Apêndice 1

\section{Estimação de Modelo com Todas as Variáveis}

\begin{tabular}{|c|c|c|}
\hline Variável & Coeficiente & Erro Padrão \\
\hline Suporte & $-1,089650 * * *$ & 0,279717 \\
\hline Demanda & $3,250501 * \star \star$ & 0,365355 \\
\hline Controle & $-0,954328^{* * *}$ & 0,331342 \\
\hline Idade & $-0,023955$ & 0,117079 \\
\hline Sexo & $4,600769 * \star *$ & 1,548697 \\
\hline Casado & 4,168706 & 8,008532 \\
\hline Solteiro & 1,043083 & 8,175797 \\
\hline Divorciado & 5,268972 & 8,419474 \\
\hline Quantidade de Filhos & 0,921707 & 1,142500 \\
\hline Possuir Dependentes & $-3,069958$ & 2,556226 \\
\hline Lecionar à Noite & 2,319385 & 1,745730 \\
\hline Lecionar pela Manhã & 10,606050 & 7,282451 \\
\hline Renda Familiar & $-0,000415^{\star * *}$ & 0,000131 \\
\hline Lecionar em IES Pública & $3,430405^{*}$ & 1,820489 \\
\hline Ser Doutor & $-0,131680$ & 2,522063 \\
\hline Ser Mestre & 0,437154 & 2,024721 \\
\hline Maior Titulação Contábeis & 1,969760 & 3,331775 \\
\hline Maior Titulação Administração & $-0,119562$ & 3,482935 \\
\hline Maior Titulação Economia & $-0,681828$ & 4,896584 \\
\hline Maior Titulação Direito & 0,761807 & 5,453118 \\
\hline Maior Titulação Outra Área & 0,801266 & 3,546956 \\
\hline Tempo Docência & $-0,067370$ & 0,134433 \\
\hline Percepção sobre sua Saúde Física & 0,234871 & 1,092445 \\
\hline Percepção sobre sua Saúde Mental & $-2,761007 * \star$ & 1,124160 \\
\hline Usar Substâncias Químicas & $-1,067266$ & 1,482670 \\
\hline Ter Doença Grave & 2,021688 & 4,224041 \\
\hline Horas Aulas Lecionadas por Semana & 0,099631 & 0,088608 \\
\hline Possuir Outra Profissão & $-2,438433$ & 1,598887 \\
\hline Ter Cargo de Gestão & 1,322541 & 1,514128 \\
\hline Se Sentir Vocacionado & 0,128018 & 1,711714 \\
\hline Satisfação com a Profissão & $-1,682574$ & 1,087556 \\
\hline Satisfação com a IES & $-0,622341$ & 1,120036 \\
\hline Satisfação com seu Gestor & 0,259252 & 0,887594 \\
\hline Satisfação com seus Alunos & $-2,155764$ & 0,898732 \\
\hline Satisfação com seus Colegas & $-1,167080$ & 1,120685 \\
\hline Satisfação com suas Disciplinas & $2,018349 *$ & 1,155641 \\
\hline Satisfação com sua Remuneração & $-1,012969$ & 0,821086 \\
\hline Constante & $96,190250^{\star \star *}$ & 13,296200 \\
\hline Prob> F & & 0 \\
\hline $\mathrm{R}^{2}$ & & 0,3689 \\
\hline $\mathrm{R}^{2}$ Ajustado & & 0,3284 \\
\hline$\star \star * \mathrm{p}<0,01,{ }^{*} \mathrm{p}<0,05$ e $* p<0,1$ & & \\
\hline
\end{tabular}

